Review article

\title{
Epidemiology and pathobiology of SARS-CoV-2 (COVID-19) in comparison with SARS, MERS: An updated overview of current knowledge and future perspectives
}

\author{
Balasubramanian Ganesh ${ }^{\text {a,** }}$, Thangarasu Rajakumar ${ }^{a}$, Mathiyazhakan Malathi ${ }^{\text {a }}$, \\ Natesan Manikandan ${ }^{\mathrm{a}}$, Jaganathasamy Nagaraj ${ }^{\mathrm{a}}$, Aridoss Santhakumar ${ }^{\mathrm{a}}$, \\ Arumugam Elangovan ${ }^{\mathrm{a}}$, Yashpal Singh Malik ${ }^{\mathrm{b}}$ \\ ${ }^{a}$ ICMR-National Institute of Epidemiology (ICMR-NIE), R-127, Second Main Road, TNHB, Ayapakkam, Chennai, 600 077, Tamil Nadu, India \\ ${ }^{\mathrm{b}}$ Indian Veterinary Research Institute (IVRI), Izatnagar, 243 122, Bareilly, Uttar Pradesh, India
}

\section{A R T I C L E I N F O}

\section{Keywords:}

COVID-19

SARS-CoV-2

SARS-CoV

MERS-CoV

Epidemiology

Pathobiology

\begin{abstract}
A B S T R A C T
Severe Acute Respiratory Syndrome-Coronavirus-2 (SARS-CoV-2) is the causative etiology of 'Corona Virus Disease-2019' (COVID-19); formerly referred as 'novel-Coronavirus-2019'. It was originated in Wuhan city, Hubei province, China in early December 2019. The World Health Organization (WHO) declared it as 'Public Health Emergency of International Concern' due to their rapid transmission and causing public and health-carerelated casualties worldwide. This review provides an updated overview of COVID-19 (SARS-CoV-2), in comparison with the etiologies of the same group viz. SARS and MERS and also its future perspectives for planning appropriate strategies for prevention, control and treatment modalities to avert similar catastrophe in near future.
\end{abstract}

\section{Introduction}

The Genus 'Coronaviruses' (CoVs) belongs to the family 'Coronaviridae' (subfamily 'Coronavirinae'). These viruses have crown-like spikes on their outer surface (Latin: Corona $=$ Crown), hence it was termed as Coronavirus. ${ }^{1}$ Commonly, CoVs spread extensively among humans, birds and other mammals and cause respiratory, neurologic, enteric and hepatic diseases. ${ }^{2}$ At present, seven human CoVs (HCoVs) types were identified that infect humans, causing diseases ranging from mild form or common cold to severe and/or fatal infections. ${ }^{3}$ Among them, four HCoVs including HCoV-OC43, HCoV-229E, HCoV-HKU1 and HCoV-NL63 are sporadically attributed to infections similar to common cold, but in rare cases can cause serious infections in infants, adolescents and elderly populations.

The remaining three Coronaviruses comprising Severe Acute Respiratory Syndrome Coronavirus (SARS-CoV), Middle East Respiratory
Syndrome Coronavirus (MERS-CoV) and Severe Acute Respiratory Syndrome Coronavirus-2 (SARS-CoV-2) can affect the lower respiratory tract and cause a severe respiratory disorder and pneumonia in humans. ${ }^{4}$ The overall comparison of the epidemiological and clinical characteristics of Severe Acute Respiratory Syndrome (SARS), Middle East Respiratory Syndrome (MERS) and Corona Virus Disease-2019 (COVID-19) is given in Table 1.

\section{Classification of CoVs}

CoVs are a positive-sense, single-stranded RNA (ssRNA) virus with a genome length from 20 to $32 \mathrm{~kb}$ and about $125 \mathrm{~nm}$ in diameter that belongs to the Coronaviridae family (subfamily Coronavirinae) of the Nidovirales Order. ${ }^{22}$ Based on the genomic structure, CoVs are divided into 4 subgroups namely, $\alpha$-CoVs, $\beta$-CoVs, $\gamma$-CoVs and $\delta$-CoVs. ${ }^{14}$ Among them, the $\alpha$ and $\beta$-CoVs infect only mammals, generally leading to

\footnotetext{
* Corresponding author. Laboratory Division, ICMR-National Institute of Epidemiology (ICMR-NIE), Indian Council of Medical Research, Department of Health

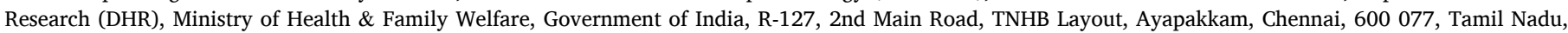
India.

E-mail addresses: niedrbganesh@gmail.com (B. Ganesh), rajkumar18388@gmail.com (T. Rajakumar), mithmals@gmail.com (M. Malathi), maninatesan87@

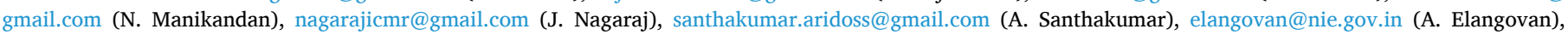
malikyps@gmail.com (Y.S. Malik).
} 
respiratory illness in humans and gastroenteritis in other animals. ${ }^{23}$ The other two subgroups, $\gamma$ and $\delta$-CoVs, infect birds and mammals. ${ }^{24}$ From the seven HCoVs, the HCoV-229E and HCoV-NL63 are $\alpha$-CoVs; whereas HCoV-OC43, HCoV-HKU1, SARS-CoV, MERS-CoV and SARS-CoV-2 are $\beta$-CoVs ${ }^{10}$ (Fig. 1).

\section{Epidemiology of SARS-CoV, MERS-CoV and SARS-CoV-2}

\subsection{Origin}

\subsection{1. $S A R S-C o V$}

A highly contagious outbreak of a respiratory infection that caused atypical pneumonia was first reported in the Guangdong Province, China in November 2002. ${ }^{25}$ The infection that was first presented with mild respiratory difficulties and acute fever, quickly developed into severe pneumonia within days of infection. ${ }^{26}$ The infection spread from human-to-human causing 'cluster of cases' or groups of illnesses among the health care personnel and was termed as SARS. The SARS-CoV was the causative agent of SARS and has quickly spread to 29 countries across the world. In total, 8098 patients and 774 deaths were reported during the time of the outbreak with a mortality rate of $9.56 \% .^{27}$ The World Health Organization (WHO) announced SARS a global public health alert on March 13, 2003.

\subsubsection{MERS-CoV}

The causative agent of MERS was first named as a novel Human Coronavirus Erasmus Medical Center (HCoV-EMC). ${ }^{28}$ The virus was first identified among humans in Jeddah, Saudi Arabia in 2012. ${ }^{29}$ In total, 2279 confirmed cases and 806 deaths of MERS-CoV were reported worldwide by the WHO (mortality rate: 35.37\%), of which 1901 confirmed cases and 732 deaths (mortality rate: $38.51 \%$ ) were from Saudi Arabia. ${ }^{9}$

\subsubsection{SARS-CoV-2}

In early December 2019, a group of local health workers reported with pneumonia-like symptoms of unidentified cause, which were epidemiologically connected to the seafood market in Wuhan city, Hubei Province, Mainland China. ${ }^{16}$ On January 7, 2020, WHO provisionally named the infection, 2019-novel Coronavirus $(2019-\mathrm{nCoV})^{30}$ and it was consequently renamed as SARS-CoV-2 by the Coronavirus Study Group (CSG) of the International Committee on Taxonomy of Viruses (ICTV) on $11^{\text {th }}$ Feb $2020^{31}$ and on the same day the disease caused by SARS-CoV-2 was called as 'COVID-19'. ${ }^{24}$ On January 30, 2020, the WHO announced the 2019-nCoV outbreak as 'Public Health Emergency of International Concern' (PHEIC), sixth and the latest in the chronological order after (i). H1N1 (2009), (ii). Polio (2014), (iii). Ebola in West Africa (2014), (iv). Zika (2016) and (v). Ebola in the Democratic Republic of Congo (2019). On March 11, 2020, the WHO declared COVID-19 as a 'pandemic'. ${ }^{32}$ As of November 30, 2020, this emerging highly infectious disease has spread to 216 countries and territories, infecting 62,195,274 individuals with 1,453,355 deaths worldwide and the mortality rate: $2.34 \%{ }^{7}$

\subsection{Transmission of SARS-CoV, MERS-CoV and SARS-CoV-2}

The SARS-CoV, MERS-CoV and SARS-CoV-2 are thought to have originated in bats based on its resemblance to the bat coronaviruses. Being zoonotic origin the CoVs can be transmitted from animal to animal (veterinary infectious diseases), animal to human (zoonotic) and human to human (anthroponoses) (Fig. 2).

\subsubsection{Animal to animal transmission}

Although CoVs are predicted to circulate for centuries in the world, the origin of CoVs remains unclear. At the starting of SARS and MERS outbreaks, civet cats and dromedary camels, respectively, were

Table 1

Epidemiological and clinical characteristics of SARS, MERS and COVID-19.

\begin{tabular}{|c|c|c|c|c|}
\hline Characteristics & SARS & MERS & COVID-19 & References \\
\hline Year of origin & November 2002 & June 2012 & December 2019 & 5 \\
\hline Etiology & SARS-CoV & MERS-CoV & SARS-CoV-2 & 5 \\
\hline Original location & Guangdong, China & Jeddah, Saudi Arabia & Wuhan, China & 6 \\
\hline Confirmed cases & 8,098 & 2,279 & $62,195,274^{\mathrm{a}}$ & 7,8 \\
\hline Mortality rate & $774(9.56 \%)$ & $806(35.37 \%)$ & $1,453,355(2.34 \%)^{\mathrm{a}}$ & $8,9,7$ \\
\hline $\begin{array}{l}\text { Number of countries } \\
\text { affected }\end{array}$ & 29 & 27 & $216^{\mathrm{a}}$ & 10 \\
\hline Natural reservoir host & Bat & Bat & Bat & 11 \\
\hline Intermediate host & Civet cats & Dromedary camel & Pangolins & 5 \\
\hline Genome length & $27.9 \mathrm{~kb}$ & $30.1 \mathrm{~kb}$ & $29.9 \mathrm{~kb}$ & 12,13 \\
\hline Genus & Beta-CoV lineage B & Beta-CoV lineage $C$ & Beta-CoV lineage B & 14,15 \\
\hline Incubation period & $2-10$ days & $2-14$ days & $1-14$ days & 11 \\
\hline $\begin{array}{l}\text { Basic reproduction } \\
\text { number }\left(\mathrm{R}_{0}\right)\end{array}$ & $2-3$ & $<1$ & 2.2 & 16 \\
\hline Transmission & $\begin{array}{l}\text { Respiratory droplets, close contact with } \\
\text { diseased patients }\end{array}$ & $\begin{array}{l}\text { Respiratory droplets, close contact with } \\
\text { diseased patients }\end{array}$ & $\begin{array}{l}\text { Respiratory droplets, close contact with } \\
\text { diseased patients }\end{array}$ & 17 \\
\hline $\begin{array}{l}\text { Human-to-human } \\
\text { transmission }\end{array}$ & Efficient & Limited & Possibly efficient & 11 \\
\hline $\begin{array}{l}\text { Predominant cellular } \\
\text { receptor }\end{array}$ & ACE2 & DPP4 (CD26) & ACE2 & 5 \\
\hline Transmission region & Globally & Regionally & Globally & 10 \\
\hline Pandemic potential & Yes & No & Yes & 11 \\
\hline Sign and symptoms & $\begin{array}{l}\text { Fever, malaise, myalgia, headache, } \\
\text { diarrhea, shivering, } \\
\text { cough, shortness of breath }\end{array}$ & $\begin{array}{l}\text { Fever, myalgia, diarrhea, cough, shortness } \\
\text { of breath }\end{array}$ & Fever, myalgia, cough, shortness of breath & 18 \\
\hline Major complications & $\begin{array}{l}\text { Pneumonia, severe acute respiratory } \\
\text { distress syndrome, } \\
\text { death }\end{array}$ & $\begin{array}{l}\text { Pneumonia, severe acute respiratory } \\
\text { distress } \\
\text { syndrome, death }\end{array}$ & $\begin{array}{l}\text { Pneumonia, severe acute respiratory } \\
\text { distress } \\
\text { syndrome, death }\end{array}$ & 18 \\
\hline Diagnosis & $\begin{array}{l}\text { RT-PCR, rRT-PCR, RT-LAMP, rRT-LAMP } \\
\text { Coronavirus detection kit }\end{array}$ & $\begin{array}{l}\text { RT-PCR, rRT-PCR, RT-LAMP, rRT-LAMP } \\
\text { Coronavirus detection kit }\end{array}$ & $\begin{array}{l}\text { RT-PCR, rRT-PCR, RT-LAMP, rRT-LAMP } \\
\text { Coronavirus detection kit }\end{array}$ & 19,20 \\
\hline Treatment & Glucocorticoid and interferon & Ritonavir and Lopinavir & Lopinavir/ritonavir (under clinical trials) & 19,21 \\
\hline
\end{tabular}

${ }^{\text {a }}$ As on $30^{\text {th }}$ November 2020, (WHO, 2020b). 


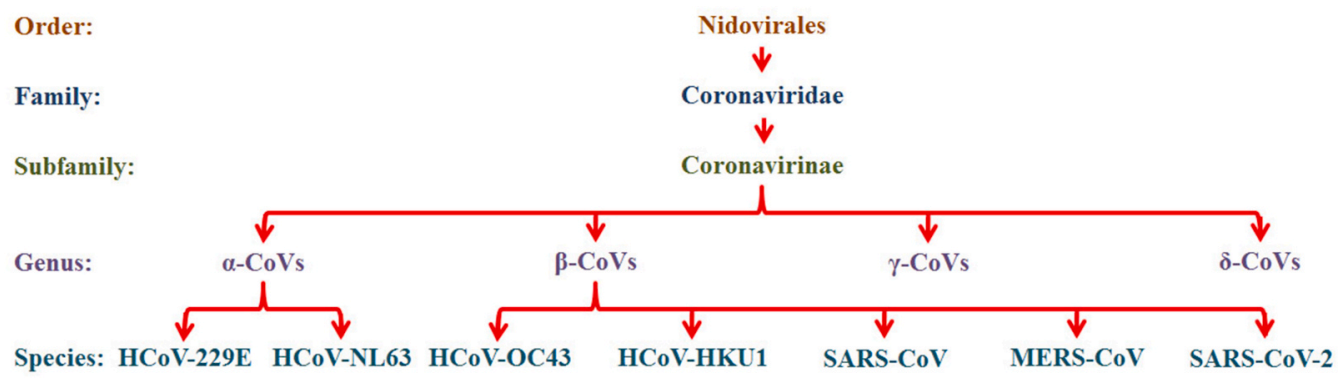

Fig. 1. Classification of coronaviruses (ICTV).

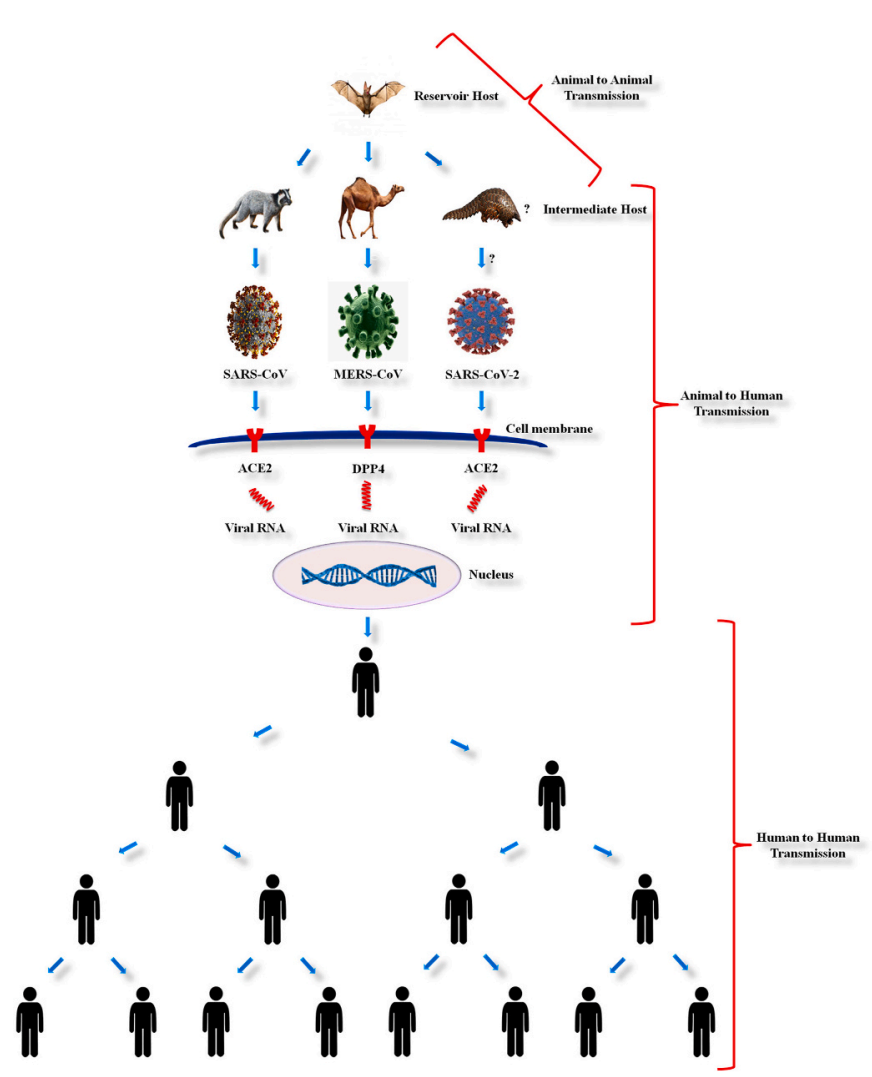

Fig. 2. Schematic representation of transmission of Severe Acute Respiratory Syndrome Coronavirus (SARS-CoV), Middle East Respiratory Syndrome Coronavirus (MERS-CoV) and Severe Acute Respiratory Syndrome Coronavirus-2 (SARS-CoV-2).

considered to be the natural source of these two HCoVs. But, ultimately molecular genetic research studies and comprehensive phylogenetic analyses of these viral etiologies has confirmed that the bats were the reservoir hosts of both SARS-CoV ${ }^{33}$ and MERS-CoV, ${ }^{34}$ which subsequently use civet cats and dromedary camels as mediator hosts previous to spreading to humans. Several theories on the origin of SARS-CoV-2 illness exist; initially, it was believed to be originated from bats, seafood and snakes that had spread among people visiting or residing in Wuhan, China and recently it is suggested to have transmitted from pangolins to humans. ${ }^{35}$

\subsubsection{Animal to human transmission}

The mode and mechanisms of transmission of SARS-CoV, MERS-CoV and SARS-CoV-2 remains obscure. Direct contact with mediator host, exposure to animals or urine of animals, consumption of milk or unprocessed meat of the infected animals were considered to be the key routes of these $\mathrm{HCoV}$ transmissions to humans. ${ }^{14}$ SARS-CoV, MERS-CoV and SARS-CoV-2 were transmitted directly to humans from market civet cats, dromedary camels and pangolins, respectively. ${ }^{1,36,37}$

\subsubsection{Human to human transmission}

SARS-CoV, MERS-CoV and SARS-CoV-2 are transmitted by humanto-human contact, or by touching surfaces contaminated by the infected person and through aerosol transmission. ${ }^{38}$ Transmission through direct human-to-human contact is most commonly reported among health care employees and primary caregivers of the diseased patient. ${ }^{39}$ These viruses spread through the respiratory droplets while sneezing or coughing, that stays on the surfaces. Human transmission can also occur upon contact with such contaminated surfaces. ${ }^{40}$ Aerosol transmission occurs when a diseased person coughs or sneezes and the resulting virus loaded droplets are propelled up to 3 feet via the air and enters the mucous membranes of the nose, eyes and mouth of peoples who are nearby. ${ }^{41}$

\subsubsection{Human to animal transmission}

Though SARS-CoV-2 said to be transmitted to human from cavedwelling bat species, recent reports have raised concerns about reverse zoonotic transmission to fur animals, zoo animals, domestic and pet animals such as dogs and cats, ${ }^{42}$ but more research is needed to be conducted in near future to prove substantially across the world through an appropriate holistic approach to address various possibilities and probabilities at different environmental conditions.

\section{Genome structure of SARS-CoV, MERS-CoV and SARS-CoV-2}

HCoVs such as SARS-CoV, MERS-CoV and SARS-CoV-2 are the main causes of severe pneumonia in humans and shared several common structural characteristics of CoVs. The genomic arrangement of CoVs is as follows: $5^{\prime}$-replicase (rep gene) ORF1ab, spike (S), envelope (E), membrane (M), nucleocapsid (N)-3' with small untranslated sections at both terminals (Fig. 3). The rep gene encodes for the non-structural proteins (NSPs) and constitutes approximately two-thirds of the viral genome. ${ }^{43}$ It has been demonstrated that the CoVs genome has different types of open reading frames (ORFs). Two out of three parts of viral RNA are mostly presented in the first ORFs (ORF1a/b) that translates into two polyproteins like pp1a and pp1ab and encodes 16 NSPs, whereas the residual ORFs encode structural and accessory proteins. The structural proteins such as spike (S), envelope (E), membrane (M) and nucleocapsid $(\mathrm{N})$ proteins and some accessory proteins are involved in the response of the host innate immune system ${ }^{4}$ (Fig. 3). The $\mathrm{S}$ protein is a transmembrane glycoprotein, which is essential and necessary for the receptor-binding and subsequent entry of the virus into the host cells. The S protein contains two subunits like S1 and S2. The S1 subunit having the receptor-binding domain (RBD) engage with host cell receptor ACE-2 in case of SARS-CoV and SARS-CoV-2 whereas in MERS-CoV with the DPP4 receptor on the host cells. The S2 subunit mediates fusion between viral and host cell membranes. ${ }^{43,44}$ The $\mathrm{S}$ protein of SARS-CoV is the most important targets for the development of SARS-CoV vaccines and therapeutics because it is involved in receptor 

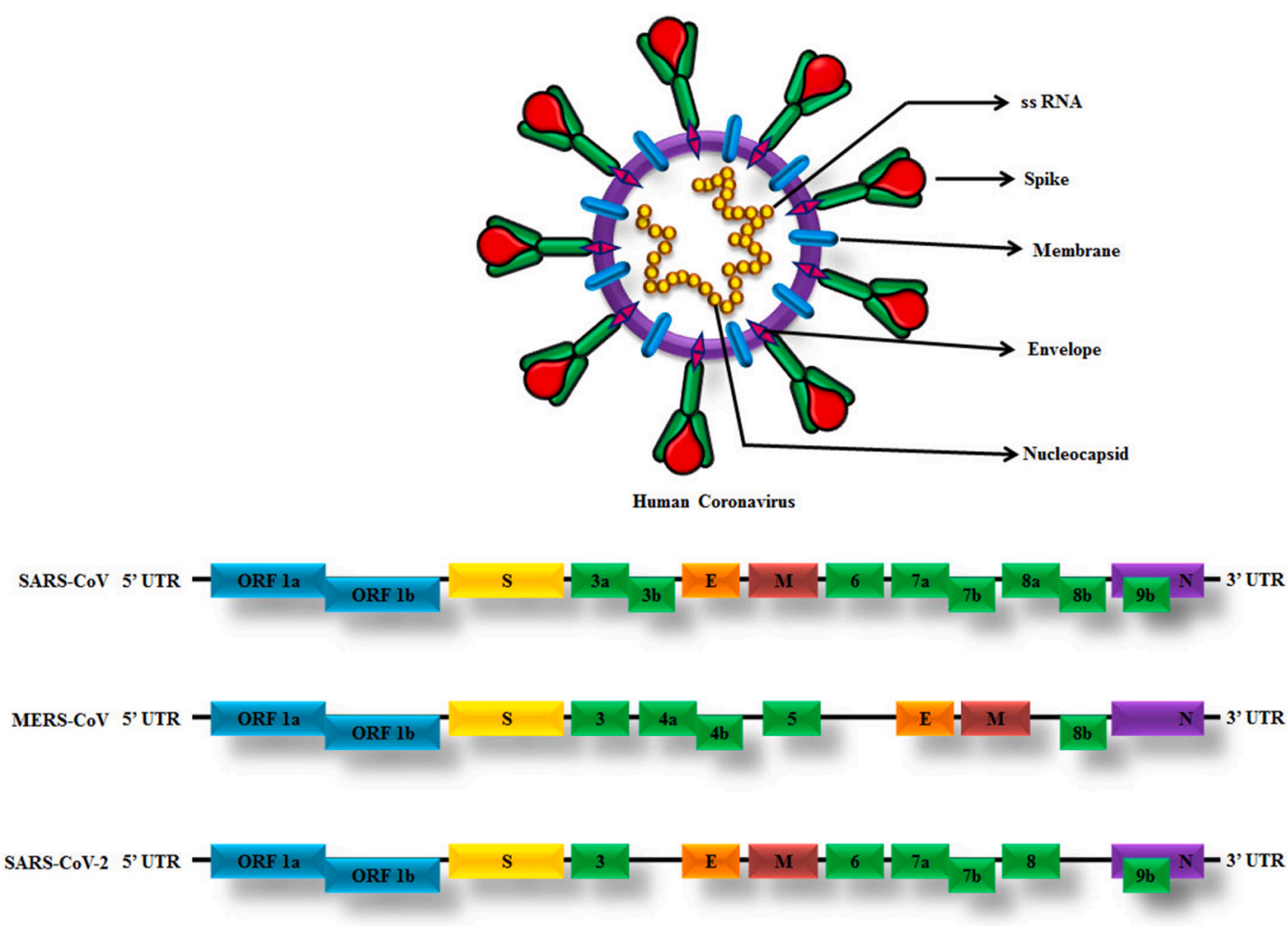

Fig. 3. Genome and genome structures of SARS-CoV, MERS-CoV and SARS-CoV-2. The genome comprises of the $5^{\prime}$-untranslated region (5'-UTR), open reading frame (ORF) 1a/b (bluebox) encoding non-structural proteins (NSP) for replication, structural proteins including spike (yellow box), envelop (orange box), membrane (maroon box) and nucleocapsid proteins (purple box), accessory proteins (green boxes) such as ORF 3, 3a, 3b, 4a, 4b, 5, 6, 7a, 7b, 8, 8a, 8b and 9b and the 3'untranslated region (3'-UTR).

recognition, virus attachment and entry in to the host cell. ${ }^{43}$ The E protein is necessary for intracellular transportation and assembly of virus, $\mathrm{M}$ protein has its function in viral assembly and morphogenesis and $\mathrm{N}$ protein is essential for the synthesis of RNA. ${ }^{10}$

The complete genome of Wuhan-Hu-1 Coronavirus (WHCV) was isolated from a COVID-19 infected pneumonia patient, an employee in the Wuhan seafood market. The genome length of SARS-CoV-2 is 29.9 $\mathrm{kb}^{12}$ and that of MERS-CoV and SARS-CoV is $30.1 \mathrm{~kb}$ and $27.9 \mathrm{~kb}$, respectively. ${ }^{13}$ The genomic sequence of SARS-CoV-2 demonstrated is identical to the previously reported SARS-CoV and MERS-CoV, but the genome composition is significantly different from SARS-CoV and MERS-CoV. ${ }^{5}$ Based on the viral genome sequencing, phylogenetic outcomes and investigations related to evolutionary patterns, the bat has been believed as the primary host of virus origin and SARS-CoV-2 might have been transmitted from bats to humans through pangolins as an intermediary host. The SARS-CoV-2 genome sequence shares $96.2 \%$ similarity to Bat-CoV-RaTG13, 79.5\% similarity to SARS-CoV and around $50 \%$ to MERS-CoV. ${ }^{45}$ Researchers discovered that the SARS-CoV-2 showed increased sequence homology to Bat-CoV-RaTG13 that was formerly found in Rhinolophus affinis (commonly called 'Horse-shoe bat') from Yunnan Province than Bat-SL-CoVZC45 and Bat-SL-CoVZC21, which reported that the Chinese chrysanthemum bat is the origin of SARS-CoV-2 and the identical sequence derived from $>1000$ metagenomic samples of the pangolin species. Pangolins were reported as the intermediate hosts, for the reason that the SARS-CoV-2 isolated from the pangolins had about $85.5 \%-92.4 \%$ similarities between the genomes of CoVs. ${ }^{46}$ Likewise, camels were reported as the intermediate hosts for MERS, since the MERS-CoV isolated from camels and humans had more than $99 \%$ similarity. ${ }^{4}$

\section{Pathobiology of SARS-CoV, MERS-CoV and SARS-CoV-2}

The $\mathrm{S}$ protein in CoVs is involved in receptor-recognition, virus attachment and entry in to the host cell. For $\beta$-CoVs, the RBD of the $S$ protein arbitrates the binding to the host receptor. SARS-CoV spike can mediate cell-cell fusion with ACE2-expressing cells at neutral $\mathrm{pH}$ and this is supported by the observation that when expressed on the cell surface and cleaved by exogenous proteases favours virus to enter the host cell. ${ }^{47}$ Dipeptidyl peptidase 4 (DPP4; also known as CD26) and angiotensin-converting enzyme 2 (ACE2) are well-known host receptors for MERS-CoV and SARS-CoV, respectively. ${ }^{48,49}$ In a similar way to SARS-CoV, the SARS-CoV-2 also makes use of ACE2 to enter into host cells. The process of ACE2 receptor and $S$ protein binding of SARS-CoV-2 is very similar to that of SARS-CoV, demonstrating that they have the same mechanism for entry into host cells. But, SARS-CoV-2 S binding to ACE2 has around 10-20 times increased binding capacity compared to the SARS-CoV. ${ }^{50}$ This may also be one among the many other factors that might favour in higher transmission rate of SARS-CoV-2 than SARS-CoV.

In the respiratory tract, for the SARS-CoV and SARS-CoV-2, ACE2 is broadly expressed in the epithelial cells of the trachea, bronchi, alveoli, alveolar monocytes and bronchial serous glands and macrophages ${ }^{51}$; but for MERS-CoV, the DPP4 expression in the respiratory tract is mostly on non-ciliated bronchial epithelial cells, type I and type II pneumocytes, endothelial cells and a little form of hematopoietic cells. ${ }^{48}$ The SAR$\mathrm{S}-\mathrm{CoV}$ and SARS-CoV-2 viruses replicate in these target cells and then the mature virions are released from the primary cells and infect new target cells; ${ }^{52}$ whereas the MERS-CoV, the DPP4 receptors are presented on the epithelial surface of different human organs such as the kidneys, thymus, lungs, liver, bone marrow and intestines. ${ }^{53}$ For the SARS-CoV and SARS-CoV-2, the respiratory secretions, droplets generated while sneezing and/or coughing, stool, sweat and urine from the infected 
patients are reported to be highly infectious to their close contacts primarily. The infectious droplets might be taken away to a distance of $\sim 1$ $\mathrm{m}$ or more due to air currents and may infect surfaces and others nearby, so stands at risk of transmission of infection.

\subsection{Clinical pathology of SARS-CoV-2}

With respect to the SARS-CoV-2 infection, the clinical pathology can be categorized into three stages viz. mild, severe and critical. ${ }^{54}$ In the mild stage of infection, the patient may or may not develop pneumonia, sometimes with symptoms of upper respiratory infection, marked by mild febrile illness with dry cough, sore throat, etc.,. ${ }^{19}$ In severe cases, the rate of respiration will be more than 30 /minute due to dyspnea, productive cough, shortness of breath and hypoxia. These symptoms develop within short duration $(24-48 \mathrm{~h})$ initial symptoms. Finally, the critical stage comprised of severe pneumonia, respiratory failure, cardiac arrest and/or multiple organ failure leads to death.

\subsection{Infection on vascular endothelium}

The presence of viral particles in the endothelium and the histological evidence of superficial and deep perivascular lymphocytic vascular infiltrates and damage with exocytosis to the dermis are observed in COVID-19 cases. $^{55}$ Infection due to COVID-19 in many cases results in endothelial dysfunction. This acts as a direct target of the virus and inflammatory cytokines. Also, it results in composing a pro-inflammatory and procoagulant state in COVID-19 patients. Around the world, there were studies being conducted on the promising therapies that impact endothelial dysfunction. ${ }^{56}$

\subsection{Organ-pathologies of heart, brain, liver, etc}

In some infected patients, microvascular steatosis and mild lobular and portal activity were recorded in hepatic tissues, interstitial mononuclear inflammatory infiltrates were found in cardiac tissues. Also the endothelial cell involvement in different organs, including the kidney, lung, heart and liver were reported. ${ }^{56}$

\subsection{Chilblains ("COVID toes")}

A study from Spain report that among children and teenagers infected with SARS-CoV-2 results in acute chilblains. It is a newly recognized clinical manifestation of COVID-19 in children and teenagers. It is also called as "COVID toes" which is a mildly symptomatic condition with an excellent prognosis. The uniqueness among these age groups showed either an asymptomatic or minimally symptomatic COVID-19 disease pattern. ${ }^{57}$

\subsection{Disseminated intravascular coagulation}

Recently, the involvement of the hemostatic system in severe COVID19 pneumonia has been identified. Manifestation of disseminated intravascular coagulopathy (DIC) seems to be responsible for worsening COVID-19 associated pneumonia and is often associated with mortality. It is reported that coagulation system is activated in many COVID-19 patients, leading to elevation of the D-dimer concentrations in patients who did not survive than those survivors. ${ }^{58}$ The association between COVID-19 and venous thromboembolism (VTE) including deep vein thrombosis (DVT) and pulmonary embolism (PE) has been reported in some clinical case reports. ${ }^{59}$ Hemostatic abnormalities associated with COVID-19 include mild thrombocytopenia (inconsistence) and increased D-dimer levels, both of which are associated with higher risk of needing mechanical ventilation, intensive care support or death. Therefore, thromboprophylaxis is considered as a good option for management of COVID-19 patients. $^{58}$ Its reported that $>70 \%$ of COVID-19 critical cases who succumb to the infection had DIC based on their laboratory findings. Another multicenteric study conducted in the USA also reported that critically ill COVID-19 patients suffered from thrombosis and bleeding. ${ }^{60}$

\subsection{Sepsis syndrome}

The endothelial cells (ECs) play a major role in several physiologic processes in humans. They control blood rheology, vasomotor tone regulation, osmotic balance and vascular barrier function. Similarly, the ECs plays crucial role in innate immune response such as sepsis as well as activation of adaptive immunity. ECs represents an important target for infection of most human viruses including SARS-CoV-2 by enhancing immune response, inducing increased tissue permeability, inflammation and contributing to the severity of the viral disease. ${ }^{56}$ COVID-19 infection has a varied clinical manifestation. In many of the infected cases, it causes asymptomatic or mild symptoms. In a few cases, immunologic complications such as macrophage activation syndrome, also known as secondary hemophagocytic lymphohistiocytosis, which results in cytokine storm syndrome and ARDS, which is fatal if not treated effectively. ${ }^{61}$

\subsection{Childhood diseases}

The study reports published so far about the COVID-19 infection among the children has shown a mild process and a good prognosis. Moreover, household contact history needs to be investigated in detail to conclude the transmission of COVID-19 infection among young children. A major problem still to explore more among young children is that the existence of viral RNA in the gastrointestinal system than in the respiratory tract to findout the transmission dynamics and pattern of spread of infection. ${ }^{62}$

\section{Diagnosis}

\subsection{Clinical diagnosis}

The following are the criteria for clinical suspects of COVID-19: Influenza-like Illness (ILI) case is defined as one with acute respiratory infection with fever $\geq 38{ }^{\circ} \mathrm{C}$ and cough; Severe Acute Respiratory Infection (SARI) case is defined as one with acute respiratory infection with fever $\geq 38{ }^{\circ} \mathrm{C}$ and cough and requiring hospitalization; other symptoms include cold, cough, sneeze, running nose, breathlessness, malaise, gastroenteritis and difficulty in breathing. Presence of SARS$\mathrm{CoV}$ is detected by an antigen-based or nucleic acid-based laboratory tests such as rapid tests and real-time RT-PCR test, respectively. Throat swab or nasopharyngeal swab is collected from the suspected cases for viral nucleic acid-based detection assays to detect current COVID-19 infection; where as blood/serum is used to detect IgM (current/recent infection) or IgG (past infection) for serosurveillance studies to estimate the prevalence of infection in the community.

\subsection{Clinical criteria for COVID-19 diagnosis}

Individuals currently suffering from ILI or symptoms with history of international travel in the last 14 days; All symptomatic (ILI symptoms) contacts of laboratory confirmed COVID-19 positive cases; All symptomatic (ILI symptoms) health care workers/frontline workers involved in containment and mitigation of COVID-19; All patients of SARI; Asymptomatic individuals who were in direct contact with a laboratory confirmed COVID-19 positives and high-risk contacts of a confirmed case to be tested once between day 5 and day 10 of coming into contact; All symptomatic ILI within hotspots/containment zones; All hospitalized patients who develop ILI symptoms (nosocomial infection) and All symptomatic ILI among returnees and migrants within 7 days of illness. Generally, when a person is tested and become positive for COVID-19, his/her family members or who were all in close contact with the 
positive is being tested. Also, the persons who had a recent travel history to the affected country or visited the endemic area or country and currently symptomatic (with the ILI) are to be tested for COVID-19.

The identification of novel coronaviruses is based on previous travel history to COVID-19 affected country, primary and secondary contacts of laboratory confirmed COVID-19 cases and the laboratory confirmed COVID-19 cases those who were without any of the above conditions (no previous travel history to COVID-19 affected countries or even no history of contact with COVID-19 confirmed cases) are termed 'community transmitted cases'. The prior symptoms of SARS, MERS and COVID-19 are much related to winter influenza and the most significant technique to discriminate pneumonia and flu is to obtain throat swabs for viral detection analysis. ${ }^{63}$

\subsection{Laboratory-based tools for COVID-19 surveillance}

Antibody-based rapid detection tests are mainly advised for surveillance activities, whereas viral antigen-based or viral nucleic acid based real-time RT-PCR is being advised for diagnosis of suspects of COVID-19 as well as the contacts of COVID-19 positives, so that after laboratory confirmation, appropriate treatment and management follow-up procedures are being followed to avert further spread to the community as well as to alleviate morbidity and prevent mortality. Gold standard frontline test for COVID-19 diagnosis is real-time PCR based molecular test, which is aimed at early virus detection. The rapid antibody test cannot replace the frontline test. The rapid antibody test is a supplementary tool to assess the prevalence of the diseases within a specific area or perimeter. The rapid antibody test will only be of utility after a minimum of 7 days of onset of symptoms. Data about these rapid tests is emerging and understanding of their utility for diagnosis is still evolving. The rapid tests are useful for epidemiological studies and surveillance purposes. All the above tests need to carry out under strict medical supervision.

\section{Prevention and control}

\subsection{Personal hygiene}

To decrease the diffusion of coronavirus, prior identification, isolation and observing social-distancing in crowded areas are crucial. ${ }^{64}$ Different types of health instruction have been provided in the community to create awareness of epidemic control and prevention, i.e., everyone are advised to wash their hands with soap and water regularly at intermittent intervals or cleaning with alcohol-based sanitizers more frequently than normal, also advised to stay at home, to avoid crowded places and also advised for home-quarantine and if necessary, limit or avoid contact with diseased persons.

\subsection{Face mask}

The surgical mask (triple layered) is advised for the general public to wear while going out to crowded places. The simple cloth masks will not protect from viral infections, it just gives a false hope that it prevents infections with COVID-19. So, the same can be made educated to the general public. And, the N95 masks are being advised for the front-line health care workers viz. doctors, nurses and paramedical staff who attend the COVID-19 positives in hospitals on a daily-basis. Be it developed countries or developing countries, most of the local governments have advised the public to wear surgical masks or N95 respirator masks when entering public places, subways or taxis for the patients with laboratory confirmed acute Influenza in Australia. ${ }^{65}$

\subsection{Countrywide lockdown}

Due to this pandemic emergency and global public health crisis, a major countrywide lockdown was implemented in India, the second largest population in the world next to China, on four-phases for a period of 68 days $(21+19+14+14)$ (to minimize the spread of infection or transmission).

Phase 1: March 25, 2020-April 14, 2020 (21 days).

Phase 2: April 15, 2020-May 3, 2020 (19 days).

Phase 3: May 4, 2020-May 17, 2020 (14 days).

Phase 4: May 18, 2020-May 31, 2020 (14 days).

\subsection{Daily fever surveillance}

Temperature screening checkpoints have been arranged to screen all travelers by using thermal scanners at railway stations, subway stations, seaport and airport terminals in an attempt for identifying suspected people with fever in general.

\subsection{Telemedicine}

Hospitals are recommending online advisories and medical facilities to suspected and symptomatic patients, which facilitates promoting awareness to the general public to avoid rushing to hospitals, thereby avoiding crowds or mass-gatherings in the hospitals, to prevent further transmission and thus decrease the possibility of being getting infected. To prevent health care employees from being infected, the National Health Commission (NHC) guaranteed adequately providing Personal Protective Equipments (PPEs) like isolation gowns, masks and gloves and issued a methodological guideline for the control and prevention of disease caused by the novel coronaviruses. ${ }^{41}$

\subsection{Isolation/Quarantine}

Isolation/Quarantine is a conventional but very effective and successful measure to counteract all lethal epidemics, but isolation/quarantine practices can be hard to implement. To prevent community transmission, travelers from China (particularly Wuhan) and other cities/countries affected with COVID-19 were advised to report their travel history and advised to self-isolation for 14 days. Furthermore, both the confirmed and suspected cases should be immediately isolated and treated in the designated hospitals in efficient isolation (facility-based quarantine) and defensive conditions to avoid further transmission of infection to others. ${ }^{66}$ Suspected person should be isolated in a separate room either in their home i.e., home quarantine or opt for facility-based quarantine. WHO proposed that patients lacking causal chronic diseases (heart or lung disease, immunodeficiency or renal failure) and with mild symptoms possibly concerned for in the home surroundings in isolation. ${ }^{67}$ Conversely, adverse cases must be hospitalized and serious cases must be admitted immediately to the ICU for appropriate treatment and medical care.

\subsection{Social distancing}

Social distancing means literally 'physical distancing', i.e., to maintain a distance of three feet is believed to be a proper distance for people to stay away from an infected patient and everyone should strictly follow the social distance (at least $1 \mathrm{~m}$ ) to reduce the risk of disease transmission. $^{68}$

\subsection{Ban on wildlife market (live/dead)/bushmeat}

Most importantly, these highly contagious pathogens of SARS and COVID-19 were originated from the wild animals. ${ }^{69}$ Hence, eating, selling and hunting of wild animals for the bushmeat, not only dangerously spoil the ecological balance, but also lead to the transmission of emerging and/or re-emerging highly infectious zoonotic diseases. ${ }^{70}$ Also, it is not only restricted to selling, hunting and eating but also the interactions and encounters with wildlife can also be a potential threat which can be part of religious or social practice, tourism or unavoidable 
encroachment of human population to the wild ecologies and diminishing habitats for wild animals due to human population explosion. Therefore, banning all wildlife markets either live or killed will be an efficient measure to prevent exotic viral infections of public health concern. ${ }^{71}$ Likewise, the wildlife ecologies should be protected and prohibited from human invasion to avoid human animal encounters/interactions, which to an extent prevent cross-spillovers between different hosts (reservoir hosts, intermediate hosts and/or accidental hosts).

\subsection{Vaccination}

An effective vaccine is the need of the hour to render immunity against COVID-19. Meanwhile adhering to non-pharmacological interventions such as social distancing, wearing masks and practicing hand hygiene are required to break the transmission chain. Vaccination is essential for control and treatment of epidemics/pandemics caused by these emerging and re-emerging exotic and highly infectious viral etiologies. Globally, research institutions and pharmaceutical companies are speeding up their research and development for developing a potential candidate vaccine against coronaviruses. The viral strains that have caused this pandemic have been isolated from infected patients. This marks the beginning of research and development of a novel coronavirus vaccine. During the outbreak of SARS and MERS, several drugs and vaccine candidates were developed and evaluated for their efficacy. Unlike bacterial infections, vaccines are more effective against viral infections than drugs. Hence, only symptomatic treatment and supportive care were followed for treating SARS-CoVs and MERS-CoVs and no specific drug was deemed effective. Vaccines based on liveattenuated or inactivated viruses, recombinant viral vectors, DNA, virus-like particles (VLPs) and soluble proteins (S glycoproteins) were studied, of which very few candidates entered the clinical phase. However, there are no commercial vaccines for SARS and MERS due to various reasons. ${ }^{10,13}$ Given the virulence of SARS, the protective efficacy of the vaccine could not be evaluated and vaccine development for MERS was delayed owing to the scarcity of suitable and cost-effective small animal models during pre-clinical experiments. But in both outbreaks, the transmission was relatively low as compared to COVID-19 and the diseases eventually ceased within a year. SARS and MERS had a higher fatality rate, but their transmission rate was low when compared to COVID-19. Only a few cases were reported for SARS after 2004 and MERS after 2016, which would have impeded potential interests in delivering the vaccines or other antiviral therapies. ${ }^{13,72}$

\subsubsection{SARS- $\mathrm{CoV}$}

Researchers have been enforced to improve $S$ protein-based vaccines to create long-term effective counter balance antibodies and/or to boostup immunity against SARS-CoV. ${ }^{43}$ Live attenuated vaccines have been investigated for SARS in animal models. ${ }^{73}$

\subsubsection{MERS-CoV}

Vaccination approaches have been developed against MERS-CoV using DNA plasmids, inactivated virus, nanoparticles, viral vectors, VLPs and recombinant protein subunits and some have been tested in animal models as well. ${ }^{74}$

\subsection{3. $S A R S-C o V-2$}

The improvements of a safe, secure and successful vaccine against SARS-CoV-2 for non-immune persons are a very urgent necessity and play an important role in the controlling of ongoing disease transmission. Further, the progress in the development of vaccines and therapies against previous coronaviruses has been helpful to a certain extent, more research and testing are required for combating the novel coronavirus more effectively and efficiently.

\section{Treatment}

\subsection{Need based therapy to alleviate symptoms (symptomatic therapy)}

There is no specific/standard antiviral treatment available for COVID-19 and there is no vaccine currently available. Preliminary, the treatment is based symptomatic and oxygen therapy that represents the major treatment intervention for patients with severe infection. Mechanical ventilation may be necessary in cases of respiratory failure refractory to oxygen therapy, whereas hemodynamic support is essential for managing septic shock. On January 28, 2020, the WHO released a document summarizing WHO guidelines and scientific evidence derived from the treatment of previous epidemics from HCoVs. This document addresses measures for recognizing and sorting patients with severe acute respiratory disease; strategies for infection prevention and control; early supportive therapy and monitoring; a guideline for laboratory diagnosis; management of respiratory failure and ARDS; management of septic shock; prevention of complications; treatments and considerations for pregnant patients. Among these recommendations, we report the strategies for addressing respiratory failure, including protective mechanical ventilation and high-flow nasal oxygen (HFNO) or noninvasive ventilation (NIV). ${ }^{75}$ Extracorporeal membrane oxygenation (ECMO) for patients with refractory hypoxemia despite lung-protective ventilation should merit consideration after a case-by-case analysis. It can be suggested for those with poor results to prone position ventilation. $^{75}$

\subsection{Host immune modulation}

Till date the studies on COVID-19 reports that the host response to SARS-CoV-2 infection is complex and highly dynamic. During the first time exposure to SARS-CoV-2, individuals have effective initial host defense in the lung and are associated with mild symptoms and disease resolution. In a few cases, viral evasion of the immune response can lead to refractory alveolar damage, ineffective lung repair mechanisms and systemic inflammation with associated organ dysfunction. ${ }^{76}$ The immune response in these patients is highly variable and can include moderate to severe systemic inflammation and/or marked systemic immune suppression. It is believed that a personalized, immunophenotype-driven approach to immunomodulation that may include anti-cytokine therapy in carefully selected patients and immunostimulatory therapies in others is the shortest path to success in the study and treatment of patients with critical illness due to COVID-19.

\subsection{Viral clearance}

The most effective way for the treatment of SARS, MERS and COVID19 is to investigate whether existing antiviral drugs are efficient. In earlier epidemics of $\beta$-coronavirus, many anti-viral drugs, like interferons (IFNs), darunavir/cobicistat (prezcobix), ribavirin and lopinavir-ritonavir were investigated with a few confirm promising in vitro outcomes. ${ }^{77}$ Lopinavir, an antiretroviral drug, inhibits the protease enzyme and in combination with another protease inhibitor, ritonavir diminishes the metabolism, thereby reducing the viral metabolism and helps in viral clearance.

\subsection{Antivirals}

At present, the in vitro antiviral efficacy of accepted drugs such as penciclovir, ribavirin, chloroquine, nafamostat, umifenovir, darunavir, arbidol and nitazoxanide are compared with that of the two broad-range antiviral medicines like favipiravir and remdesivir for COVID-19 therapy. Among the investigated drugs, both chloroquine and remdesivir were observed to be better efficient in treating for COVID-19. ${ }^{78}$ Chloroquine is an old Chinese drug extensively applied for antimalarial treatment that is well-known to prevent virus-cell binding and is 
involved in the glycosylation of ACE2 cellular receptors and SARS-CoV, representing the ACE2-SARS-CoV less efficient in interaction. There is also in vitro confirmation that chloroquine significantly inhibits the spreading of SARS-CoV by interfering with ACE2 in Vero E6 cells ${ }^{79}$ and might be efficient in preventing cellular entry of SARS-CoV-2. ${ }^{78}$

Remdesivir is an adenosine analog medicine presently under the improvement of the Ebola virus disease and is efficient in a wide range of viruses including SARS-CoV, MERS-CoV and SARS-CoV-2. ${ }^{80-82}$ There is now in vitro confirmation that remdesivir possibly successful in controlling SARS-CoV-2 infection. ${ }^{78}$ Favilavir, previously considered as Fapilavir, was the first anti-novel coronavirus medicine that was accepted to be available in the market by the National Medical Products Administration since the outbreak. The medicine was produced by Zhejiang Hisun Pharmaceutical Company and is estimated to have an important function in treating and preventing the epidemic.

Till date, ribavirin and ribavirin with different types of IFNs have been the main regular therapeutics endeavored in patients with SARS and MERS. ${ }^{83,84}$ Ribavirin is a nucleoside analogue, has a broad-range of antiviral properties via preventing viral RNA synthesis and mRNA capping. ${ }^{85}$ Previous research reported that the combined ribavirin with alisporivir for improved antiviral property against SARS-CoV and MERS-CoV. ${ }^{86}$ IFN, thymosin and intravenous $\gamma$-globulin were considered to improve our immune system to combat with SARS-CoV and MERS-CoV as well as SARS-CoV-2. ${ }^{6}$ Researchers earlier proved that the protease inhibitors such as ritonavir and lopinavir, drugs for human immunodeficiency virus (HIV) infection, could enhance the results against SARS-CoV ${ }^{77}$ and MERS-CoV. ${ }^{21}$ It has reported that viral loads of a COVID-19 patient in Korea had considerably reduced after treated with lopinavir/ritonavir. ${ }^{87}$

\subsection{Convalescent plasma or plasma therapy}

An easy but very effective treatment approach is currently carried out using convalescent plasma or serum from patients who have recovered from the coronavirus infection and to treat very severely infected cases. Patients with the resolute viral disease may have a particular antibody reaction that may be used to counteract viruses in newly diseased persons. This modality was successfully carried out during the Ebola outbreaks in West Africa during 2014-2015 ${ }^{88}$ and also successfully employed for the SARS-CoV ${ }^{89}$ and MERS-CoV. ${ }^{90}$ Although, the development of convalescent plasma therapy is of partial assistance in an outbreak condition because the exponential augmentation of diseased patients exceeds than the number of plasma donors. ${ }^{1}$ This therapy has been applied during the outbreaks when no exact vaccines or medicines were available for treatment. ${ }^{90}$

\subsection{Anticoagulants as therapeutics}

\subsubsection{Heparin}

Most commonly use anticoagulant as a COVID-19 remedy is low molecular weight heparin (LMWH). It has been implicated in binding to COVID-19 spike proteins as well as in down regulation of interleukin-6 which has been shown to be elevated in COVID-19 patients. ${ }^{91}$ A recent study demonstrated the interaction between the SARS-CoV-2 spike S1 protein receptor binding domain (SARS-CoV-2 S1 RBD) and heparin, suggesting the development of heparin-based therapeutics. ${ }^{92}$ It is of great interest to develop the novel heparin-based compounds for COVID-19. ${ }^{93}$

\subsubsection{Dipyridamole}

Dipyridamole (DIP), an antiplatelet agent, acts as a phosphodiesterase (PDE) inhibitor that increases intracellular cAMP/cGMP. ${ }^{94}$ Apart from the well-known antiplatelet function, DIP may provide potential therapeutic benefits to patients with COVID-19. The clinical trials in China have demonstrated that DIP has a broad spectrum antiviral activity, particularly efficacious against the positive-stranded RNA viruses. $^{95}$

\subsection{Use of ACE2 inhibitors}

ACE2 receptor is required for virus entry into the host cell. Inhibiting this receptor might successfully restrict virus replication in the body. Selective ACE2 inhibitor, DX600, may show beneficial results in case of SARS-CoV-2 infection, however, its clinical significance is yet to be studied. ${ }^{96}$

\section{Conclusion and future perspectives}

Since, there is no specific therapeutics or efficient vaccines for novel coronavirus resulting in COVID-19. Researchers are currently working on developing an appropriate, safe and effective vaccine candidates and antiviral drugs for prevention and control of the deadly novel coronavirus disease. The outbreaks of SARS-CoV, MERS-CoV and SARS-CoV-2, propose that coronaviruses cause an enduring threat to human life even in the modern era. The best hope we can rely on is that the outbreak will ultimately come to a control and the population's immune memory for the coronavirus i.e., 'herd immunity' will naturally control further spread. But, we should not forget the lessons learned from this pandemic and we should be prepared well in advance, precisely act and initiate an appropriate preventive measures for the next wave of outbreak of coronavirus or any other exotic viruses in the near future if the necessity arise. When an epidemic occurs, it is extremely necessary to quickly discover and isolate the pathogen to develop improved diagnostic methods. In the early phase of disease outbreak, improving the treatment efficiency and clinical characteristics, defining suspected patients and places, inventing the diagnostic measures, analyzing transmission patterns, making a proper quarantine strategy and isolating infectious patients are all the essential priorities to address and are required to be rapidly implemented to avoid catastrophic effect.

\section{Author contributions}

BG conceptualized the framework. TR, MM, NM, JN and AS performed the literature search. TR, JN and AS performed the data analysis. BG and TR prepared the first draft of the manuscript. AE and YPS critically reviewed and revised the manuscript. All authors have read and approved the final draft of the manuscript.

\section{Funding}

The author(s) received no external funding for the research, authorship, and/or publication of this article.

\section{Declaration of competing interest}

The author(s) declared no potential conflicts of interest with respect to the research, authorship, and/or publication of this article.

\section{Acknowledgments}

The Institutional Publication Committee (IPC) of ICMR-National Institute of Epidemiology, Chennai and Indian Council of Medical Research (ICMR), New Delhi for approval of the review manuscript for publication.

\section{References}

1 Rabi FA, Al Zoubi MS, Kasasbeh GA, Salameh DM, Al-Nasser AD. SARS-CoV-2 and coronavirus disease 2019: what we know so far. Pathogens. 2020;9:E231.

2 Weiss SR, Leibowitz JL. Coronavirus pathogenesis. Adv Virus Res. 2011;81:85-164. 3 Dhama K, Sharun K, Tiwari R, et al. COVID-19, an emerging coronavirus infection: advances and prospects in designing and developing vaccines, immunotherapeutics, and therapeutics. Hum Vaccines Immunother. 2020:1-7. 
4 Cui J, Li F, Shi ZL. Origin and evolution of pathogenic coronaviruses. Nat Rev Microbiol. 2019;17:181-192.

5 Prompetchara E, Ketloy C, Palaga T. Immune responses in COVID-19 and potential vaccines: lessons learned from SARS and MERS epidemic. Asian Pac J Allergy Immunol. 2020;38:1-9.

6 Xie M, Chen Q. Insight into 2019 novel coronavirus - an updated interim review and lessons from SARS-CoV and MERS-CoV. Int J Infect Dis. 2020;94:119-124.

7 WHO. Coronavirus disease 2019 (COVID-19) situation report as of 30th november 2020 (10:23 am CET). https://covid19. who.int/; 2020. Accessed November 30, 2020.

8 WHO: SARS (severe acute respiratory syndrome). https://www.who.int/ith/diseases /sars/en/; 2020. Accessed February 12, 2020.

9 WHO. Middle East Respiratory Syndrome Coronavirus (MERS-CoV)-Saudi Arabia. WHO; 2018. www.who.int/csr/don/28-december-2018-mers-saudi-arabia/en/.

10 Song Z, Xu Y, Bao L, et al. From SARS to MERS, thrusting coronaviruses into the spotlight. Viruses. 2019;11:59.

11 Lee PI, Hsueh PR. Emerging threats from zoonotic coronaviruses-from SARS and MERS to 2019-nCoV. J Microbiol Immunol Infect. 2020;(20):30011-30016. pii: S1684 1182.

12 Wu F, Zhao S, Yu B, et al. A new coronavirus associated with human respiratory disease in China. Nature. 2020;579:265-269.

13 de Wit E, van Doremalen N, Falzarano D, Munster VJ. SARS and MERS: recent insights into emerging coronaviruses. Nat Rev Microbiol. 2016;14:523-534.

14 Yin Y, Wunderink RG. MERS, SARS and other coronaviruses as causes of pneumonia. Respirology. 2018;23:130-137.

15 Fung SY, Yuen KS, Ye ZW, Chan CP, Jin DY. A tug-of-war between severe acute respiratory syndrome coronavirus 2 and host antiviral defence: lessons from other pathogenic viruses. Emerg Microb Infect. 2020;9:558-570.

16 Zhu N, Zhang D, Wang W, et al. A novel coronavirus from patients with pneumonia in China, 2019. N Engl J Med. 2020;382:727-733.

17 Tu YF, Chien CS, Yarmishyn AA, et al. A review of SARS-CoV-2 and the ongoing clinical trials. Int J Mol Sci. 2020;21:E2657.

18 Lippi G, Plebani M. The novel coronavirus (2019-nCoV) outbreak: think the unthinkable and be prepared to face the challenge. In: Diagnosis (Berl); 2020. pii:/j/d x.ahead-of-print/dx-2020-0015/dx-2020-0015.xml.

19 Xu Z, Shi L, Wang Y, et al. Pathological findings of COVID-19 associated with acute respiratory distress syndrome. Lancet Respir Med. 2020;8:420-422.

20 Shirato K, Yano T, Senba S, et al. Detection of Middle East respiratory syndrome coronavirus using reverse transcription loop-mediated isothermal amplification (RTLAMP). Virol J. 2014;11:139.

21 Arabi YM, Asiri AY, Assiri AM, et al. Treatment of Middle East respiratory syndrome with a combination of lopinavir/ritonavir and interferon- $\beta 1 \mathrm{~b}$ (MIRACLE trial): statistical analysis plan for a recursive two-stage group sequential randomized controlled trial. Trials. 2020;21:8.

22 Shereen MA, Khan S, Kazmi A, Bashir N, Siddique R. COVID-19 infection: origin, transmission, and characteristics of human coronaviruses. J Adv Res. 2020;24:91-98.

23 Zhou P, Fan H, Lan T, et al. Fatal swine acute diarrhoea syndrome caused by an HKU2-related coronavirus of bat origin. Nature. 2018;556:255-258.

24 Chen N, Zhou M, Dong X, et al. Epidemiological and clinical characteristics of 99 cases of 2019 novel coronavirus pneumonia in Wuhan, China: a descriptive study. Lancet. 2020;395:507-513.

25 Peng GW, He JF, Lin JY, et al. Epidemiological study on severe acute respiratory syndrome in Guangdong province. Zhonghua Liuxingbingxue Zazhi. 2003;24:350-352.

26 Tsang KW, Ho PL, Ooi GC, et al. A cluster of cases of severe acute respiratory syndrome in Hong Kong. N Engl J Med. 2003;348:1977-1985.

27 SARS. Severe acute respiratory syndrome. Wkly Epidemiol Rec. 2003;78:81-83.

28 Butler D. Clusters of coronavirus cases put scientists on alert. Nature. 2012;492: 166-167.

29 Zaki AM, van Boheemen S, Bestebroer TM, Osterhaus AD, Fouchier RA. Isolation of a novel coronavirus from a man with pneumonia in Saudi Arabia. N Engl J Med. 2012; 367:1814-1820.

30 Huang C, Wang Y, Li X, et al. Clinical features of patients infected with 2019 novel coronavirus in Wuhan, China. Lancet. 2020;395:497-506.

31 Gorbalenya AE, Baker SC, Baric RS, et al. Severe acute respiratory syndrome-related coronavirus: the species and its viruses-a statement of the coronavirus study group. Bio Rxiv. 2020:2020, 02.07.937862.

32 Li X, Wang W, Zhao X, et al. Transmission dynamics and evolutionary history of 2019-nCoV. J Med Virol. 2020;92:501-511.

$33 \mathrm{Li}$ W, Shi Z, Yu M, et al. Bats are natural reservoirs of SARS-like coronaviruses. Science. 2005;310:676-679.

34 Ithete NL, Stoffberg S, Corman VM, et al. Close relative of human Middle East respiratory syndrome coronavirus in bat, South Africa. Emerg Infect Dis. 2013;19: 1697-1699.

35 WHO: World health organization: Coronavirus. https://www.who.int/health-to pics/coronavirus; 2020. Accessed February 8, 2020.

36 Guan Y, Zheng BJ, He YQ, et al. Isolation and characterization of viruses related to the SARS coronavirus from animals in southern China. Science. 2003;302:276-278.

37 Hemida MG, Perera RA, Wang P, et al. Middle East Respiratory Syndrome (MERS) coronavirus seroprevalence in domestic livestock in Saudi Arabia, 2010 to 2013. Euro Surveill. 2013;18:20659.

38 Al-Abdallat MM, Payne DC, Alqasrawi S, et al. Hospital-associated outbreak of Middle East respiratory syndrome coronavirus: a serologic, epidemiologic, and clinical description. Clin Infect Dis. 2014;59:1225-1233.

39 Chowell G, Abdirizak F, Lee S, et al. Transmission characteristics of MERS and SARS in the healthcare setting: a comparative study. BMC Med. 2015;13:210.
40 Olsen SJ, Chang HL, Cheung TY, et al. Transmission of the severe acute respiratory syndrome on aircraft. $N$ Engl J Med. 2003;349:2416-2422.

41 Yang Y, Peng F, Wang R, et al. The deadly coronaviruses: the 2003 SARS pandemic and the 2020 novel coronavirus epidemic in China. J Autoimmun. 2020;109, 102434.

42 AFCD. Detection of low level of COVID-19 virus in pet dog. www.afcd.gov.hk/engl ish/publications/publications_press/pr2335.html (accessed March 24, 2020).

43 Du L, He Y, Zhou Y, Liu S, Zheng BJ, Jiang S. The spike protein of SARS-CoV-a target for vaccine and therapeutic development. Nat Rev Microbiol. 2009;7:226-236.

44 Xia S, Liu Q, Wang Q, et al. Middle East respiratory syndrome coronavirus (MERSCoV) entry inhibitors targeting spike protein. Virus Res. 2014;194:200-210.

45 Guo YR, Cao QD, Hong ZS, et al. The origin, transmission and clinical therapies on coronavirus disease 2019 (COVID-19) outbreak - an update on the status. Mil Med Res. 2020;7:11.

46 Lam TT, Shum MH, Zhu HC, et al. Identifying SARS-CoV-2 related coronaviruses in Malayan pangolins. Nature. 2020. https://doi.org/10.1038/s41586-020-2169-0.

$47 \mathrm{Li}$ F. Structure, function, and evolution of coronavirus spike proteins. Annu Rev Virol. 2016;3:237-261.

48 Raj VS, Mou H, Smits SL, et al. Dipeptidyl peptidase 4 is a functional receptor for the emerging human coronavirus-EMC. Nature. 2013;495:251-254.

49 Kuhn JH, Li W, Choe H, Farzan M. Angiotensin-converting enzyme 2: a functional receptor for SARS coronavirus. Cell Mol Life Sci. 2004;61:2738-2743.

50 Wrapp D, Wang N, Corbett KS, et al. Cryo-EM structure of the 2019-nCoV spike in the prefusion conformation. Science. 2020;367:1260-1263.

51 Kuba K, Imai Y, Rao S, et al. A crucial role of angiotensin converting enzyme 2 (ACE2) in SARS coronavirus-induced lung injury. Nat Med. 2005;11:875-879.

52 Qinfen Z, Jinming C, Xiaojun H, et al. The life cycle of SARS coronavirus in Vero E6 cells. J Med Virol. 2004;73:332-337.

53 Boonacker E, Van Noorden CJ. The multifunctional or moonlighting protein CD26/ DPPIV. Eur J Cell Biol. 2003;82:53-73.

54 He F, Deng Y, Li W. Coronavirus disease 2019: what we know? J Med Virol. 2020;92: 719-725.

55 Colmenero I, Santonja C, Alonso-Riaño M, et al. SARS-CoV-2 endothelial infection causes COVID-19 chilblains: histopathological, immunohistochemical and ultraestructural study of 7 paediatric cases. Br J Dermatol. 2020. https://doi.org/ 10.1111/bjd.19327.

56 Pons S, Fodil S, Azoulay E, Zafrani L. The vascular endothelium: the cornerstone of organ dysfunction in severe SARS-CoV-2 infection. Crit Care. 2020;24:353.

57 Andina D, Noguera-Morel L, Bascuas-Arribas M, Gaitero-Tristán J, AlonsoCadenas JA, Escalada-Pellitero S. Chilblains in children in the setting of COVID-19 pandemic. Pediatr Dermatol. 2020;37:406-411.

58 Tang N, Li D, Wang X, Sun Z. Abnormal coagulation parameters are associated with poor prognosis in patients with novel coronavirus pneumonia. $J$ Thromb Haemostasis. 2020;18:844-847.

59 Danzi GB, Loffi M, Galeazzi G, Gherbesi E. Acute pulmonary embolism and COVID19 pneumonia: a random association? Eur Heart J. 2020;41:1858.

60 Al-Samkari H, Karp Leaf RS, Dzik WH, et al. COVID-19 and coagulation: bleeding and thrombotic manifestations of SARS-CoV-2 infection. Blood. 2020;136:489-500.

61 Soy M, Keser G, Atagündüz P, Tabak F, Atagündüz I, Kayhan S. Cytokine storm in COVID-19: pathogenesis and overview of anti-inflammatory agents used in treatment. Clin Rheumatol. 2020;39:2085-2094.

62 Chen Z, Tong L, Zhou Y, et al. Childhood COVID-19: a multicentre retrospective study. Clin Microbiol Infect. 2020;S1198-743X(20), 30359-1.

63 Zeng Q, Khan K, Wu J, Zhu H. The utility of preemptive mass influenza vaccination in controlling a SARS outbreak during flu season. Math Biosci Eng. 2007:4:739-754.

64 Lau JT, Tsui H, Lau M, Yang X. SARS transmission, risk factors, and prevention in Hong Kong. Emerg Infect Dis. 2004;10:587-592.

65 Johnson DF, Druce JD, Birch C, Grayson ML. A quantitative assessment of the efficacy of surgical and N95 masks to filter influenza virus in patients with acute influenza infection. Clin Infect Dis. 2009;49:275-277.

66 Xu J, Zhao S, Teng T, et al. Systematic comparison of two animal-to-human transmitted human coronaviruses: SARS-CoV-2 and SARS-CoV. Viruses. 2020;12: E244.

67 WHO. Home care for patients with suspected novel coronavirus (nCoV) infection presenting with mild symptoms and management of contacts: interim Guidance (in Chinese) https://www.who.int/publications-detail/homecarefor-patients-with -suspected-novel-coronavirus-(ncov)-infection-presentingwith mild-symptoms-and-management-of-contacts. 2020d.

68 Yi Y, Lagniton PNP, Ye S, Li E, Xu RH. COVID-19: what has been learned and to be learned about the novel coronavirus disease. Int J Biol Sci. 2020;16:1753-1766.

$69 \mathrm{Lu} \mathrm{H}$, Stratton CW, Tang YW. Outbreak of pneumonia of unknown etiology in Wuhan, China: the mystery and the miracle. J Med Virol. 2020;92:401-402.

70 Rouquet P, Froment JM, Bermejo M, et al. Wild animal mortality monitoring and human Ebola outbreaks, Gabon and Republic of Congo, 2001-2003. Emerg Infect Dis. $2005 ; 11: 283-290$.

71 Yoo JH. The fight against the 2019-nCoV outbreak: an arduous March has just begun. J Kor Med Sci. 2020;35:e56.

72 Padron-Regalado E. Vaccines for SARS-CoV-2: lessons from other coronavirus strains. Infect Dis Ther. 2020;9:1-20.

73 Roper RL, Rehm KE. SARS vaccines: where are we? Expert Rev Vaccines. 2009;8: 887-898.

74 Xu J, Jia W, Wang P, et al. Antibodies and vaccines against Middle East respiratory syndrome coronavirus. Emerg Microb Infect. 2019;8:841-856.

75 Cascella M, Rajnik M, Cuomo A, Dulebohn SC, Di Napoli R. Features, evaluation and treatment coronavirus (COVID-19). In: Stat Pearls. Treasure Island (FL). Stat Pearls Publishing; 2020. 
76 Hall MW, Joshi I, Leal L, Ooi EE. Immune modulation in COVID-19: strategic considerations for personalized therapeutic intervention. Clin Infect Dis. 2020. ciaa 904.

77 Chu CM, Cheng VC, Hung IF, et al. Role of lopinavir/ritonavir in the treatment of SARS: initial virological and clinical findings. Thorax. 2004;59:252-256.

78 Wang M, Cao R, Zhang L, et al. Remdesivir and chloroquine effectively inhibit the recently emerged novel coronavirus (2019-nCoV) in vitro. Cell Res. 2020;30:269-271.

79 Vincent MJ, Bergeron E, Benjannet S, et al. Chloroquine is a potent inhibitor of SARS coronavirus infection and spread. Virol J. 2005;2:69.

80 Sheahan TP, Sims AC, Graham RL, et al. Broad-spectrum antiviral GS-5734 inhibits both epidemic and zoonotic coronaviruses. Sci Transl Med. 2017;9. pii: eaal3653.

81 Mulangu S, Dodd LE, Davey Jr RT, et al. A randomized, controlled trial of Ebola virus disease therapeutics. N Engl J Med. 2019;381:2293-2303.

82 Holshue ML, De Bolt C, Lindquist S, et al. First case of 2019 novel coronavirus in the United States. N Engl J Med. 2020;382:929-936.

83 Morgenstern B, Michaelis M, Baer PC, Doerr HW, Cinatl Jr J. Ribavirin and interferon-beta synergistically inhibit SARS-associated coronavirus replication in animal and human cell lines. Biochem Biophys Res Commun. 2005;326:905-908.

84 Omrani AS, Saad MM, Baig K, et al. Ribavirin and interferon alfa-2a for severe Middle East respiratory syndrome coronavirus infection: a retrospective cohort study. Lancet Infect Dis. 2014;14:1090-1095.

85 von Grotthuss M, Wyrwicz LS, Rychlewski L. mRNA cap-1 methyltransferase in the SARS genome. Cell. 2003;113:701-702.

86 de Wilde AH, Falzarano D, Zevenhoven-Dobbe JC, et al. Alisporivir inhibits MERSand SARS-coronavirus replication in cell culture, but not SARS-coronavirus infection in a mouse model. Virus Res. 2017;228:7-13.
$87 \mathrm{Lim}$ J, Jeon S, Shin HY, et al. Case of the index patient who caused tertiary transmission of COVID-19 infection in Korea: the application of lopinavir/ritonavir for the treatment of COVID-19 infected pneumonia monitored by quantitative RTPCR. J Kor Med Sci. 2020;35:e79.

88 Kraft CS, Hewlett AL, Koepsell S, et al. The use of TKM-100802 and convalescent plasma in 2 patients with Ebola virus disease in the United States. Clin Infect Dis. 2015;61:496-502.

89 Mair-Jenkins J, Saavedra-Campos M, Baillie JK, et al. The effectiveness of convalescent plasma and hyperimmune immunoglobulin for the treatment of severe acute respiratory infections of viral etiology: a systematic review and exploratory meta-analysis. J Infect Dis. 2015;211:80-90.

90 Arabi Y, Balkhy $\mathrm{H}$, Hajeer AH, et al. Feasibility, safety, clinical, and laboratory effects of convalescent plasma therapy for patients with Middle East respiratory syndrome coronavirus infection: a study protocol. SpringerPlus. 2015;4:709.

91 Mummery RS, Rider CC. Characterization of the heparin-binding properties of IL-6. J Immunol. 2000;165:5671-5679.

92 Microft-West C, Su D, Elli S, et al. The 2019 coronavirus (SARS-CoV-2) surface protein (Spike) S1 receptor binding domain undergoes conformational change upon heparin binding. Bio Rxiv. 2020. https://doi.org/10.1101/2020.02.29.971093.

93 Zhang J, Xie B, Hashimoto K. Current status of potential therapeutic candidates for the COVID-19 crisis. Brain Behav Immun. 2020;87:59-73.

94 Gresele P, Momi S, Falcinelli E. Anti-platelet therapy: phosphodiesterase inhibitors. Br J Clin Pharmacol. 2011;72:634-646.

95 Xie H. Efficacy of dipyridamole in the treatment of 116 children with acute upper respiratory tract infections. Chin J School Doct. 2010;24:921.

96 Huang L, Sexton DJ, Skogerson K, et al. Novel peptide inhibitors of angiotensinconverting enzyme 2. J Biol Chem. 2003;278:15532-15540. 